\title{
Stage 1 hybrid palliation for hypoplastic left heart syndrome-assessment of contemporary patterns of use: An analysis of The Society of Thoracic Surgeons Congenital Heart Surgery Database
}

Ryan R. Davies, MD

See related article on pages 195-202.

Since the first report by Gibbs and colleagues ${ }^{1}$ in 1993 , hybrid palliation for children with hypoplastic left heart syndrome (HLHS) has emerged as an alternative to an early modified stage 1 Norwood procedure ${ }^{2}$ for initial palliation. Different centers have advocated a variety of indications for hybrid palliation, including the first stage palliation in all patients, ${ }^{3}$ selective use in some patients, ${ }^{4}$ initial palliation in high-risk patients, ${ }^{5}$ or as a stabilization maneuver among children presenting in shock followed by an early stage 1 Norwood procedure. ${ }^{6}$ The hybrid procedure, therefore, may consist of branch pulmonary artery banding alone or in combination with ductal stenting, and subsequent management may include a return to the standard 3-stage palliation, ${ }^{5,6}$ or initial treatment with a comprehensive first and second stage. ${ }^{3,5}$ The variability in patient selection, procedural details, and subsequent management makes it difficult to identify the optimal use of hybrid palliation.

The current analysis of The Society of Thoracic Surgeons Congenital Heart Surgery Database (STS-CHSD) by Karamlou and colleagues ${ }^{7}$ confirms this variability. Their descriptive article provides a snapshot of patterns of use between 2010 and 2012. The most important finding is confirmation of the variability in the use of the procedure. The use ranged from $0 \%$ to $100 \%$ of patients with HLHS; subsequent procedures vary. Notably, the use of the hybrid procedure was higher at centers with overall lower volume, lower HLHS volume, and higher mortality after the stage 1 Norwood procedure.

Unfortunately, limitations of the STS-CHSD prevent a more revealing analysis. Although mortality rates for both the hybrid and the Norwood procedures vary widely

\footnotetext{
From the Nemours Cardiac Center, A.I. duPont Hospital for Children, Wilmington, Del and Thomas Jefferson University, Philadelphia, Pa.

Disclosures: Author has nothing to disclose with regard to commercial support. Received for publication Sept 27, 2014; accepted for publication Sept 29, 2014 Address for reprints: Ryan R. Davies, MD, Nemours Cardiac Center, A.I. duPont Hospital for Children, 1600 Rockland Road, Wilmington, DE 19803 (E-mail: rdavies@nemours.org).

J Thorac Cardiovasc Surg 2015;149:203-4 $0022-5223 / \$ 36.00$

Copyright (c) 2015 by The American Association for Thoracic Surgery http://dx.doi.org/10.1016/j.jtcvs.2014.09.106
}

between centers, without risk adjustment one can only speculate as to the causes. Based on the limited number of risk factors presented, the cohort of patients undergoing hybrid palliation is at higher risk. However, whether risk varies between centers is not clear. Although the authors suggest that centers with higher Norwood mortality may preferentially choose the possibly less technically demanding hybrid palliation as a strategy to reduce HLHS mortality, without risk adjustment it is not possible to fully characterize the variation in hybrid use or reasons for differential mortality with HLHS between centers. As the authors note, a risk-adjusted analysis would be an important next step.

The grouping of all patients into 1 hybrid category also limits the usefulness of the analysis. Based on currently available data, it is unlikely that all HLHS patients will benefit from the hybrid procedure. However, selective use of different strategies (pulmonary artery banding, ductal stenting, early Norwood, later comprehensive palliation) may result in overall improvements in HLHS outcomes. It would be valuable to understand the use of these strategies in a broad population, rather than the limited experience of individual centers. ${ }^{3-6}$

Despite these limitations, this article provides a unique descriptive analysis of the current patterns of use of the hybrid procedure throughout the STS-CHSD cohort. Subsequent analyses directed at understanding changing patterns of use over time, risk-adjusted outcomes, and variation in management strategies have the potential to identify optimal management strategies in individual patients.

\section{References}

1. Gibbs JL, Wren C, Watterson KG, Hunter S, Hamilton JR. Stenting of the arteria duct combined with banding of the pulmonary arteries and atrial septectomy or septostomy: a new approach to palliation for the hypoplastic left heart syndrome. Br Heart J. 1993;69:551-5.

2. Norwood WI, Lang P, Hansen DD. Physiologic repair of aortic atresia-hypoplastic left heart syndrome. N Engl J Med. 1983;308:23-6.

3. Galantowicz M, Cheatham JP, Phillips A, Cua CL, Hoffman TM, Hill SL, et al. Hybrid approach for hypoplastic left heart syndrome: intermediate results after the learning curve. Ann Thorac Surg. 2008;85:2063-70; discussion 2070-1.

4. Baba K, Chaturvedi R, Lee KJ, Caldarone CA, Benson LN. Fate of the ductal stent after hybrid palliation for hypoplastic left heart syndrome. Ann Thorac Surg. 2013; 95:1660-4.

5. Davies RR, Radtke WA, Bhat MA, Baffa JM, Woodford E, Pizarro C. Hybrid palliation for critical systemic outflow obstruction: neither rapid stage 1 Norwood nor 
comprehensive stage 2 mitigate consequences of early risk factors. $J$ Thorac Cardiovasc Surg. 2015;149:192-203.

6. Gomide M, Furci B, Mimic B, Brown KL, Hsia TY, Yates R, et al. Rapid 2-stage Norwood I for high-risk hypoplastic left heart syndrome and variants. J Thorac Cardiovasc Surg. 2013;146:1146-51; discussion 1151-2.
7. Karamlou T, Overman D, Hill KD, Wallace A, Pasquali SK, Jacobs JP, et al. Stage 1 hybrid palliation for hypoplastic left heart syndrome-assessment of contemporary patterns of use: An analysis of The Society of Thoracic Surgeons Congenital Heart Surgery Database. J Thorac Cardiovasc Surg. 2015;149: 195-202. 